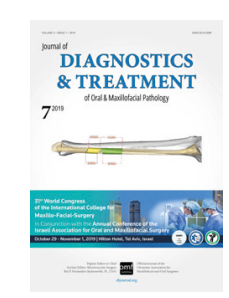

Parasitic Infection: Case Report

\title{
Paragonimiasis with Oral Cavity Colonization: First Case Report
}

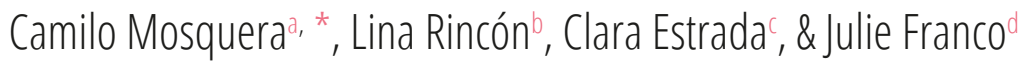

\section{S U M M A R Y}

The purpose of this case report is to share a new clinical colonization of a zoonosis condition. This is the case of a 39-year-old female patient who presented to the Emergency Department with a Paragonimus colonization of oral cavity after consumption of raw crab. This article shows the lab works and clinical challenges that Oral and Maxillo-Facial Surgery Department had to overcome to successfully treat this patient and clearly demonstrates that complete medical record continues to be a fundamental tool for correct targeting towards the diagnosis and treatment of any pathological entity.

$\mathrm{P}$ aragonimiasis is a zoonosis caused by adult trematodes of the genus Paragonimus. It manifests itself as chronic and limited pathology localized particularly in the lungs and sometimes extension in extra pulmonary sites. The definitive host of these parasites consists of wild carnivorous mammalian varieties, however, humans and domestic animals become infected by eating raw or undercooked crustaceans and shellfish infested by the organism. ${ }^{1}$

Although the disease is usually caused when the parasite is located in the lungs, severe symptoms such as diarrhea, abdominal pain, urticaria, eosinophilia, fever and adynamia may develop during the first few weeks of inoculation prior to the onset of pulmonary symptoms such as cough, hemoptysis and chest pain. ${ }^{2}$
There is very little literature that reports involvement by paragonimiasis in maxillofacial region, and there is no report of oral cavity involvement.

\section{CASE}

A 39-year-old female patient, with no relevant medical history, was admitted to the Emergency Department with a clinical picture of 2 months of evolution consisting of facial edema in the left buccal region associated with sensation of peribuccal tingling, dysarthria and pain; without fever, no secretions or history of dental pain. Physical examination showed normal vital signs and alteration of left buccal contour by indurated mass, without ulcers, painful

a DDS, Oral and Maxillofacial Surgeon; Clinical Professor, National University of Colombia, Bogotá, D.C., Colombia

${ }^{b}$ DDS, Oral and Maxillofacial Surgeon; Director, Oral and Maxillofacial Surgery Department, El Tunal Hospital, Bogotá, D.C., Colombia

c DDS, Oral and Maxillofacial Surgeon, National University of Colombia, Bogotá, D.C., Colombia

${ }^{d}$ DDS, Chief Resident, Oral and Maxillofacial Surgery, National University of Colombia, Bogotá, D.C., Colombia

*Corresponding author`s address: 111311, Colombia, Bogotá, D.C., Carrera

$22 \# 45$ c-36 consultorio 309 . Phone Number: (+57) 315-3538966

E-mail: camosquerag@unal.edu.co (Camilo Mosquera)

Instagram: camilomaxilo

Paper received 06 June 2019

Accepted 05 July 2019

Available online 31 July 2019

http://dx.doi.org/10.23999/j.dtomp.2019.7.4

(C) 2019 OMF Publishing, LLC. This is an open access article under the CC BY license (http://creativecommons.org/licenses/by-nc/4.0/) 
to palpation. The intraoral examination revealed a mass on the left lateral border of the tongue, painful to palpation, without signs of infection. It was considered that lesions were highly suggestive of neoplasia, for which head computed tomography (CT) (Fig 1) and blood lab test were ordered, which showed leukocytosis associated with neutrophilia and high C-reactive protein (CRP) levels (Table 1). Therefore, it was decided to perform an incisional biopsy of the left lateral border of tongue (Fig 2) and left cheek mucosa; abscess in both areas with secretion brown purulent material was found, also with a small black foreign body (Fig 3) which was sent together with the tissue to histopathological study. Patient was discharged with oral antibiotic regimen and biopsy results were going to be checked in the clinic. The patient was re-admitted to the Emergency Department 3 days after, due to severe pain, edema in the right face (Fig 4) and pleuritic chest pain, vital signs were normal. Consult to Oral and MaxilloFacial Surgery (OMFS) Department was requested and during patient questioning it was documented

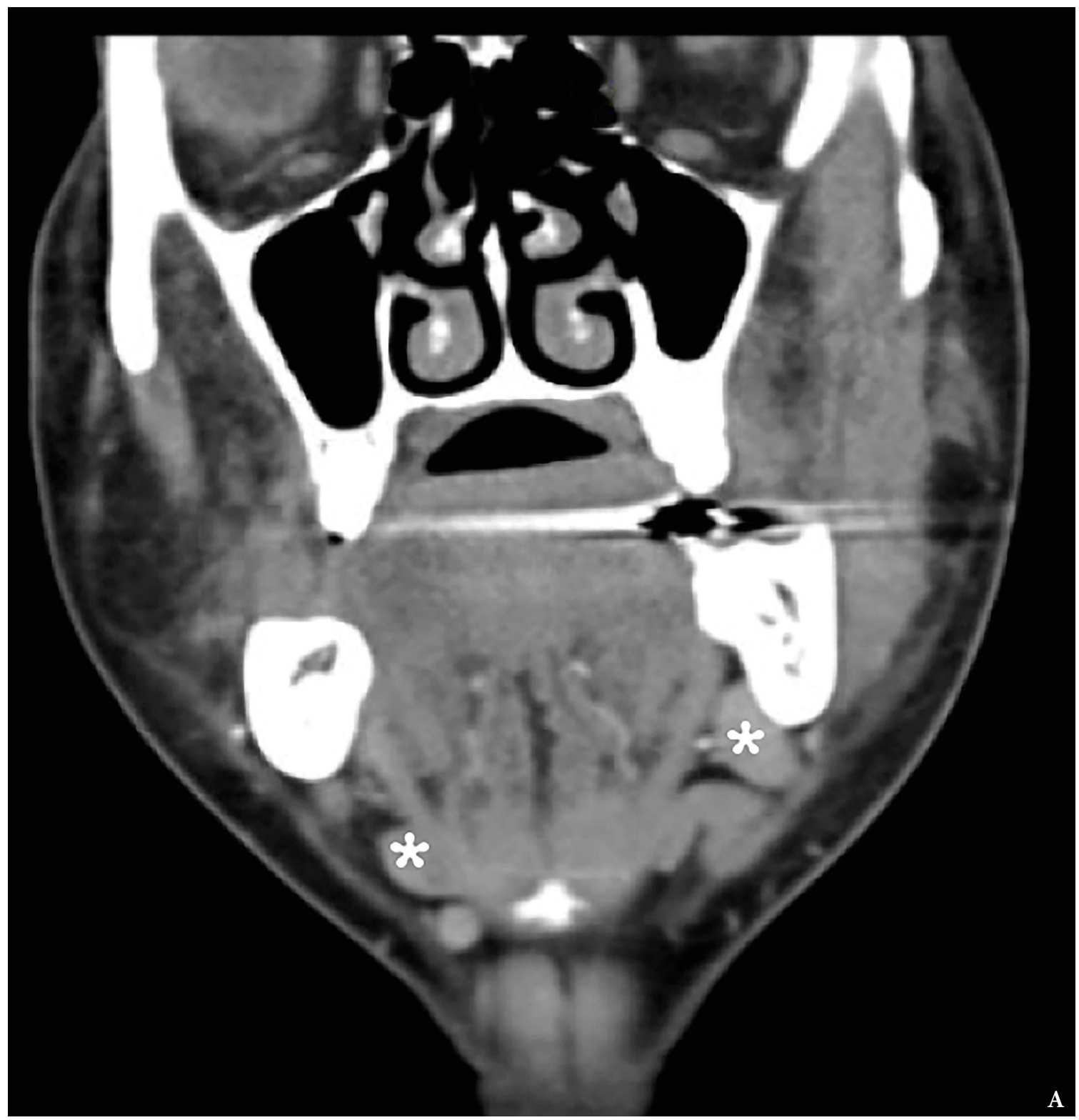

FIGURE 1. Contrast enhanced computed tomography $(\mathbf{A}, \mathbf{B})$ shows lesions with inflammatory component in left mental region and left floor of mouth, reactive cervical lymph nodes (asterisks). (Fig 1 continued on next page.) 


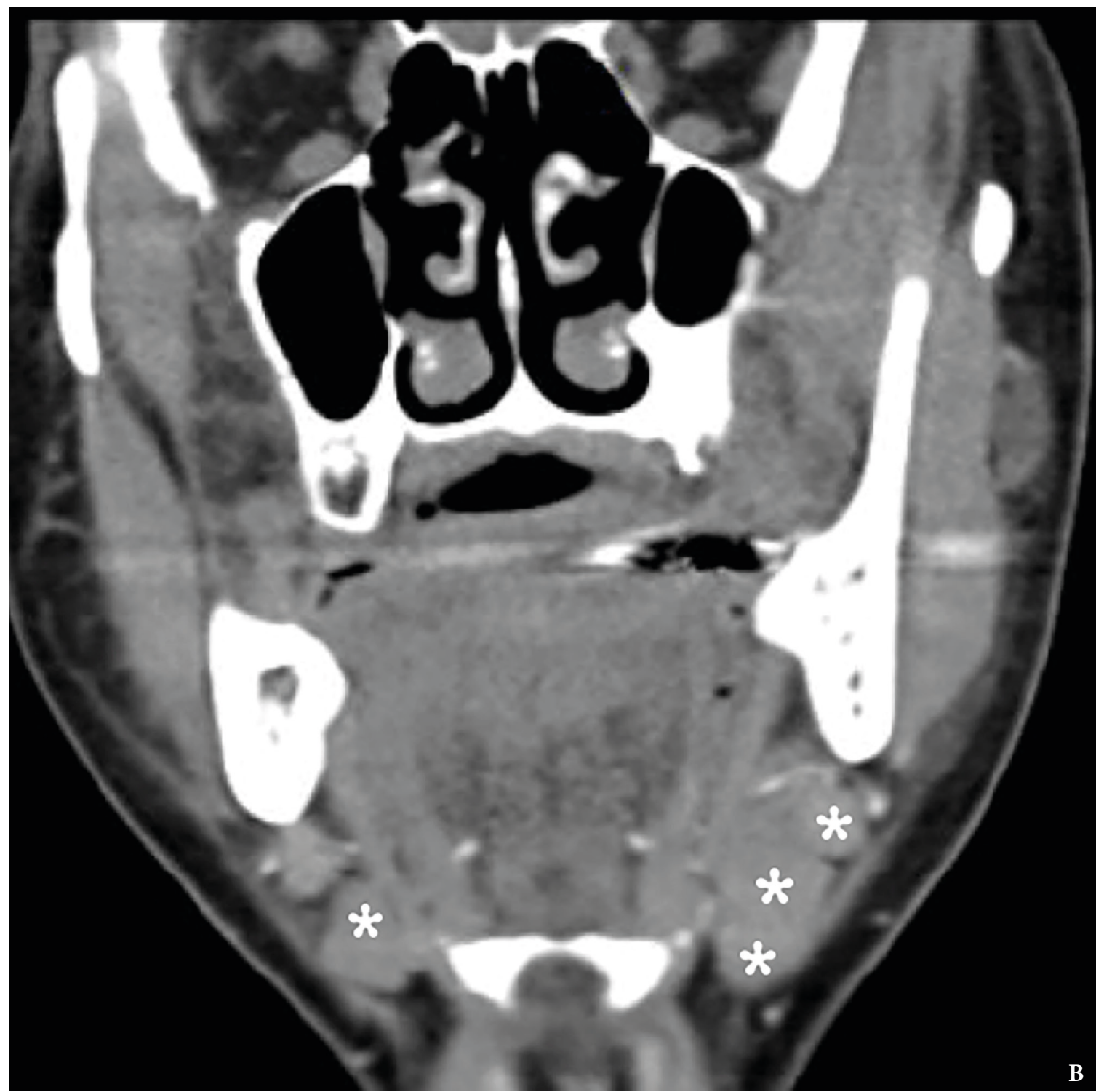

FIGURE 1 (cont'd). Contrast enhanced computed tomography (A, B) shows lesions with inflammatory component in left mental region and left floor of mouth, reactive cervical lymph nodes (asterisks).

an exposure antecedent to raw crab consumption 2 months prior to appearance of clinical picture of migratory facial nodules, reason why it was suspected paragonimiasis, therefore antibiotic scheme begun with penicillin + clindamycin; blood test and chest $\mathrm{x}$-ray were also ordered. Lab works showed increased leukocytosis and eosinophilia compared to previous results and previously (Table 2). The chest x-ray (Fig 5) showed left pleural effusion with right basal areas of fibrosis and lamellar atelectasis. The high resolution pulmonary CT scan showed signs of basal pneumonia, and the antibiotic scheme was escalated to piperacillin/tazobactam. With the new findings, a coproscopy was requested which ruled out the presence of intestinal parasites in sample; It was decided to start praziquantel (600mg every 8 hours), however, it was not possible to administer the drug immediately due to lack of availability in the country, therefore, albendazole was started on the day while the praziquantel drug was being obtained. Before antiparasitic onset, a significant increase of leukocytosis and eosinophilia levels was observed that were slightly stabilized during the management with albendazole. 
TABLE 1. Admission laboratories.

\begin{tabular}{|l|c|c|}
\hline \multicolumn{1}{|c|}{ Tests } & Results & Units \\
\hline White blood cells (WBC) & $18,500^{*}$ & $\mu \mathrm{L}$ \\
\hline Neutrophils & $13,810^{*}$ & $\mu \mathrm{L}$ \\
\hline Lymphocytes & 3,380 & $\mu \mathrm{L}$ \\
\hline Monocytes & 910 & $\mu \mathrm{L}$ \\
\hline Basophils & 40 & $\mu \mathrm{L}$ \\
\hline Eosinophils & 410 & $\mu \mathrm{L}$ \\
\hline Hemoglobin & 14.5 & $\mathrm{~g} / \mathrm{dL}$ \\
\hline Hematocrit & 43.1 & $\%$ \\
\hline Mean corpuscular volume (MCV) & 91.8 & $\mathrm{fL}$ \\
\hline Mean corpuscular hemoglobin (MCH) & 30.9 & $\mathrm{pg}$ \\
\hline Platelets & 598,000 & $\mu \mathrm{L}$ \\
\hline C-reactive protein (CRP) & 10.75 & $\mathrm{mg} / \mathrm{dL}$ \\
\hline Blood urea nitrogen (BUN) & 9.15 & $\mathrm{mg} / \mathrm{dL}$ \\
\hline Creatinine & 0.6 & $\mathrm{mg} / \mathrm{dL}$ \\
\hline
\end{tabular}

Abbreviations: $\mu \mathrm{L}$, microliters; g, grams; dL, deciliters; fL, femtoliters; pg, picograms; $\mathrm{mg}$, milligrams

* Superscript asterisk indicates about increased rates.

TABLE 2. Readmission to Emergency Room.

\begin{tabular}{|l|c|c|}
\hline \multicolumn{1}{|c|}{ Tests } & Results & Units \\
\hline White blood cells (WBC) & $23,580^{*}$ & $\mu \mathrm{L}$ \\
\hline Neutrophils & 9,360 & $\mu \mathrm{L}$ \\
\hline Lymphocytes & 4,13 & $\mu \mathrm{L}$ \\
\hline Monocytes & 940 & $\mu \mathrm{L}$ \\
\hline Basophils & 50 & $\mu \mathrm{L}$ \\
\hline Eosinophils & $9,100^{*}$ & $\mu \mathrm{L}$ \\
\hline Hemoglobin & 13.3 & $\mathrm{~g} / \mathrm{dL}$ \\
\hline Hematocrit & 39.5 & $\%$ \\
\hline Mean corpuscular volume (MCV) & 92.4 & $\mathrm{fL}$ \\
\hline Mean corpuscular hemoglobin (MCH) & 31.1 & $\mathrm{pg}$ \\
\hline Platelets & 567,000 & $\mu \mathrm{L}$ \\
\hline Blood urea nitrogen (BUN) & 9.47 & $\mathrm{mg} / \mathrm{dL}$ \\
\hline Creatinine & 0.7 & $\mathrm{mg} / \mathrm{dL}$ \\
\hline
\end{tabular}

Abbreviations: $\mu \mathrm{L}$, microliters; g, grams; dL, deciliters; fL, femtoliters; pg, picograms; $\mathrm{mg}$, milligrams.

* Superscript asterisk indicates about increased rates. 

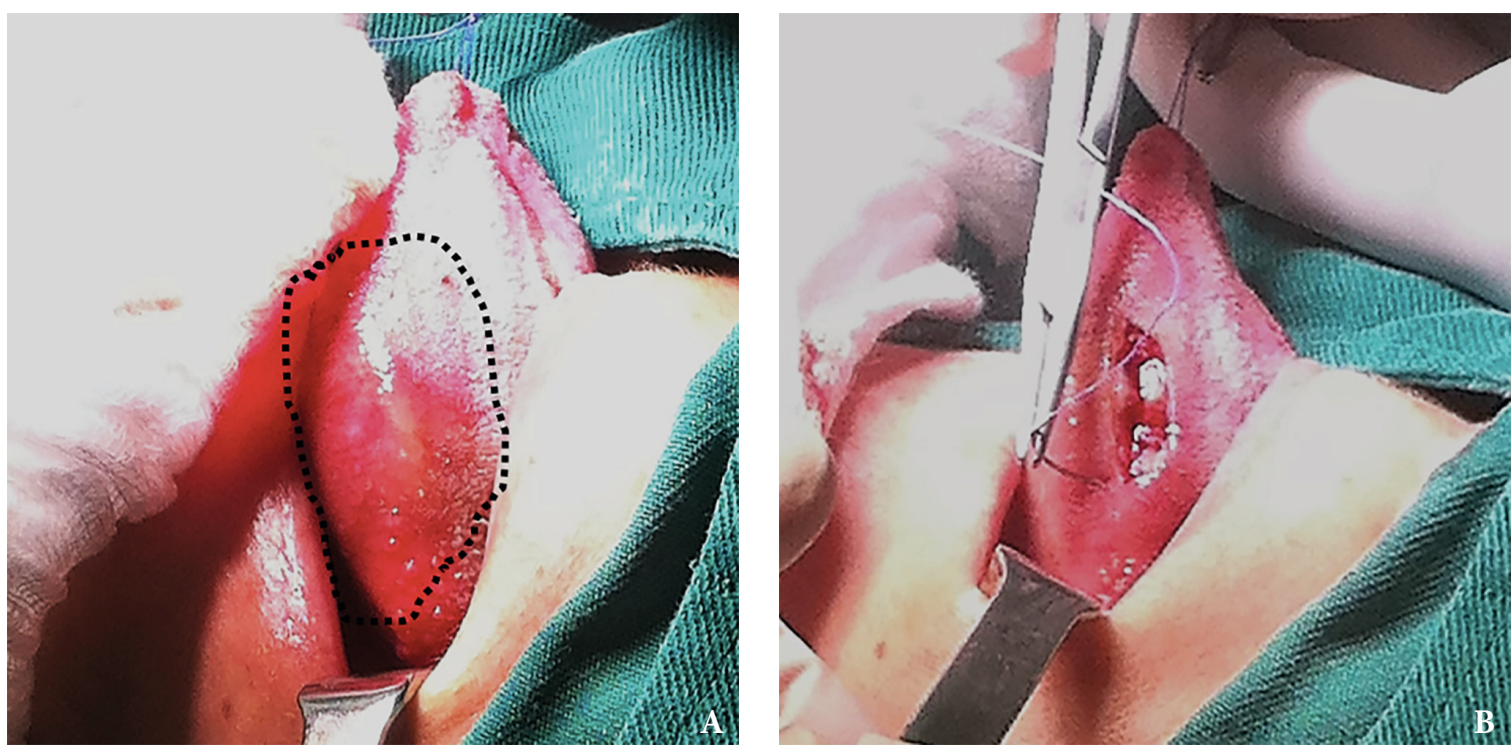

FIGURE 2. Intraoperative pictures of the left lateral tongue `s biopsy: A, black dotes indicates the biopsy `s area; $\mathbf{B}$, suturing.

Pathologic report was received indicating chronic inflammatory process with high leukocyte infiltrate and foreign body corresponding to adult form with degenerative changes of a Paragonimus westermani (Fig 6) confirming diagnosis of paragonimiasis with colonization in the oral cavity. Two weeks later, praziquantel was obtained and $600 \mathrm{mg}$ oral doses were initiated every 8 hours in a 3 -day regimen. The day after, the patient showed significant improvement in general conditions with decreased facial edema and no respiratory symptoms. Control labs evidenced decrease of leukocytosis and eosinophilia with complete resolution at the end of the anti-parasitic scheme, reason why medical discharge was given two days later. The patient attended 1 month after to control appointment with laboratories that showed normal values and clinical examination revealed total resolution of facial edema (Fig 7). Control chest $\mathrm{x}$-ray showed partial resolution of pleural effusion (Fig 5C).
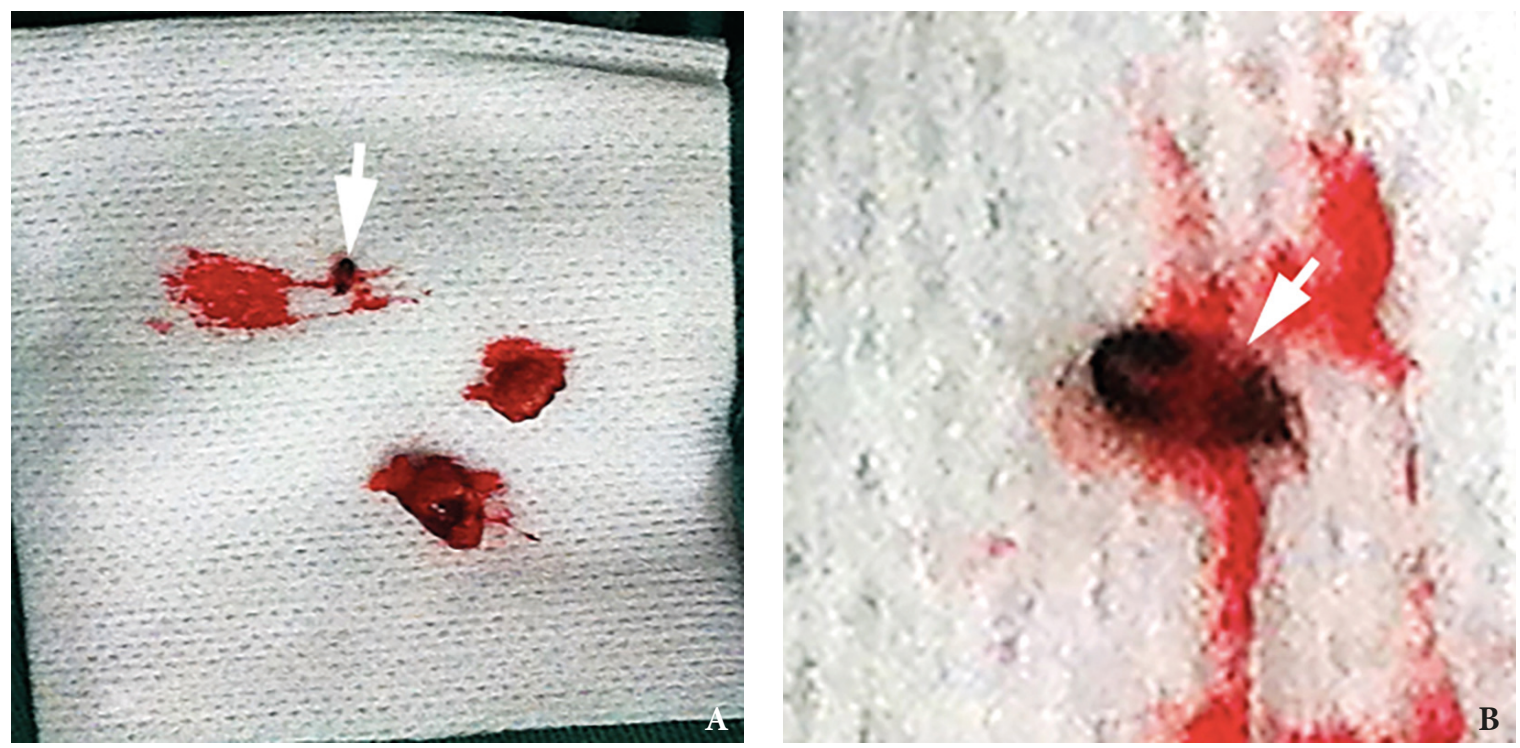

FIGURE 3. Clinical pictures of specimens obtained with left lateral tongue (A, B: image $\mathbf{B}$ is an enlarged image $\mathbf{A})$ and left cheek mucosa (C, D: image $\mathbf{D}$ is an enlarged image $\mathbf{C}$ ) biopsy. Black foreign bodies are indicated by arrows. (FIGURE $\mathbf{3}$ continued on next page.) 

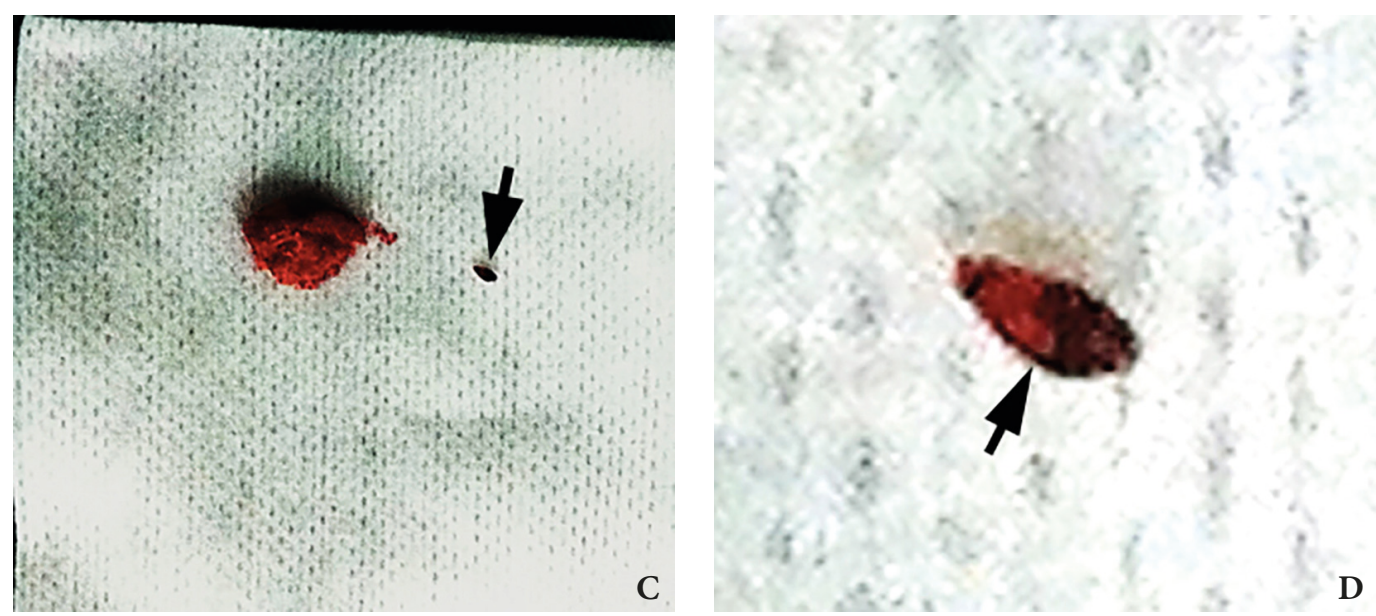

FIGURE 3 (cont'd). Clinical pictures of specimens obtained with left lateral tongue (A, B: image $\mathbf{B}$ is an enlarged image $\mathbf{A}$ ) and left cheek mucosa (C, D: image $\mathbf{D}$ is an enlarged image $\mathbf{C}$ ) biopsy. Black foreign bodies are indicated by arrows.

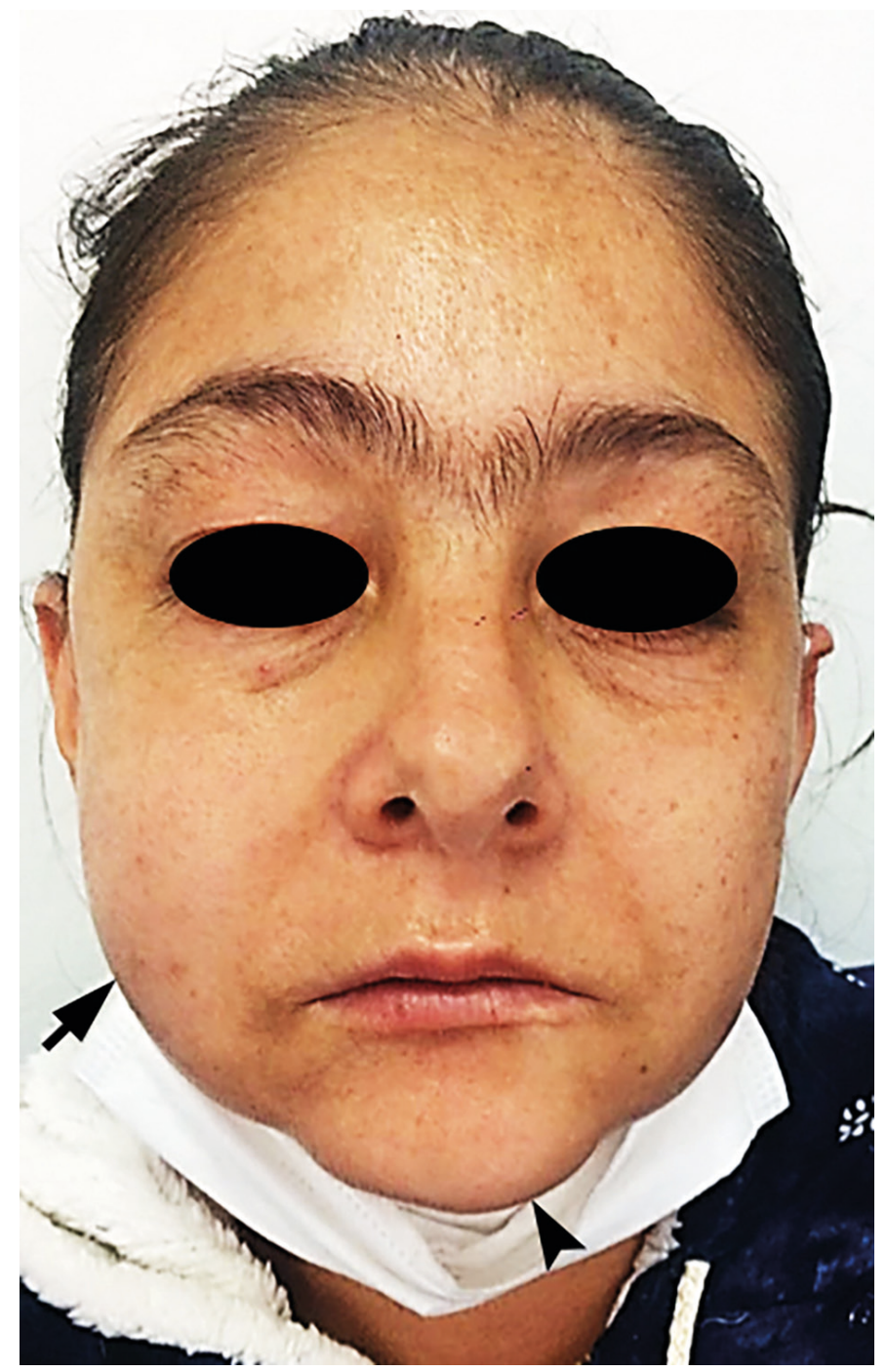

FIGURE 4. Patient showing important swelling of right hemiface (arrow) and left mental zone (arrowhead). 

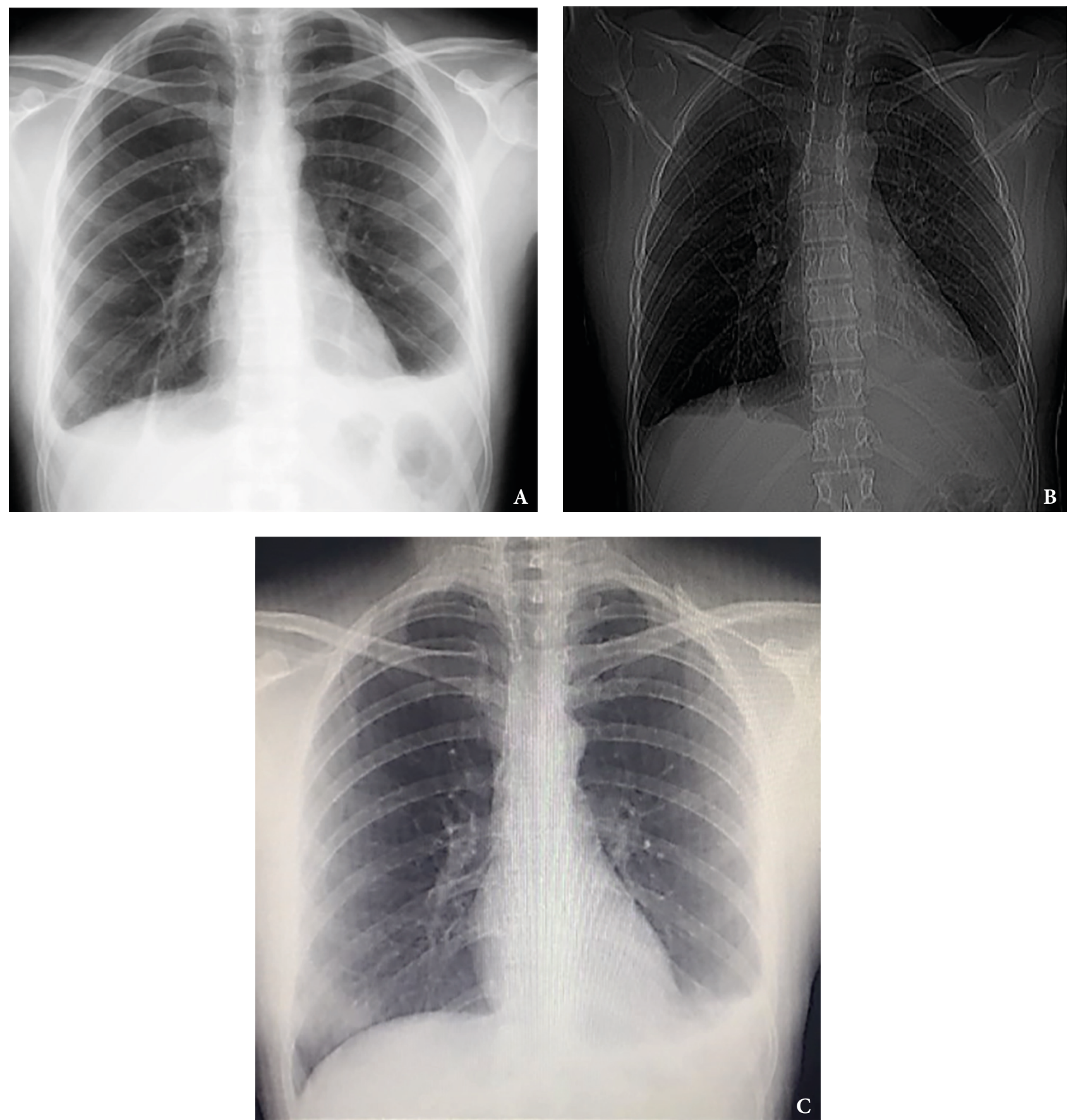

FIGURE 5. Chronologic follow-up (A, initial x-ray; $\mathbf{B}$, x-ray upon treatment) of chest x-rays showing pleural effusion and its resolution 1 month post-op (C). 


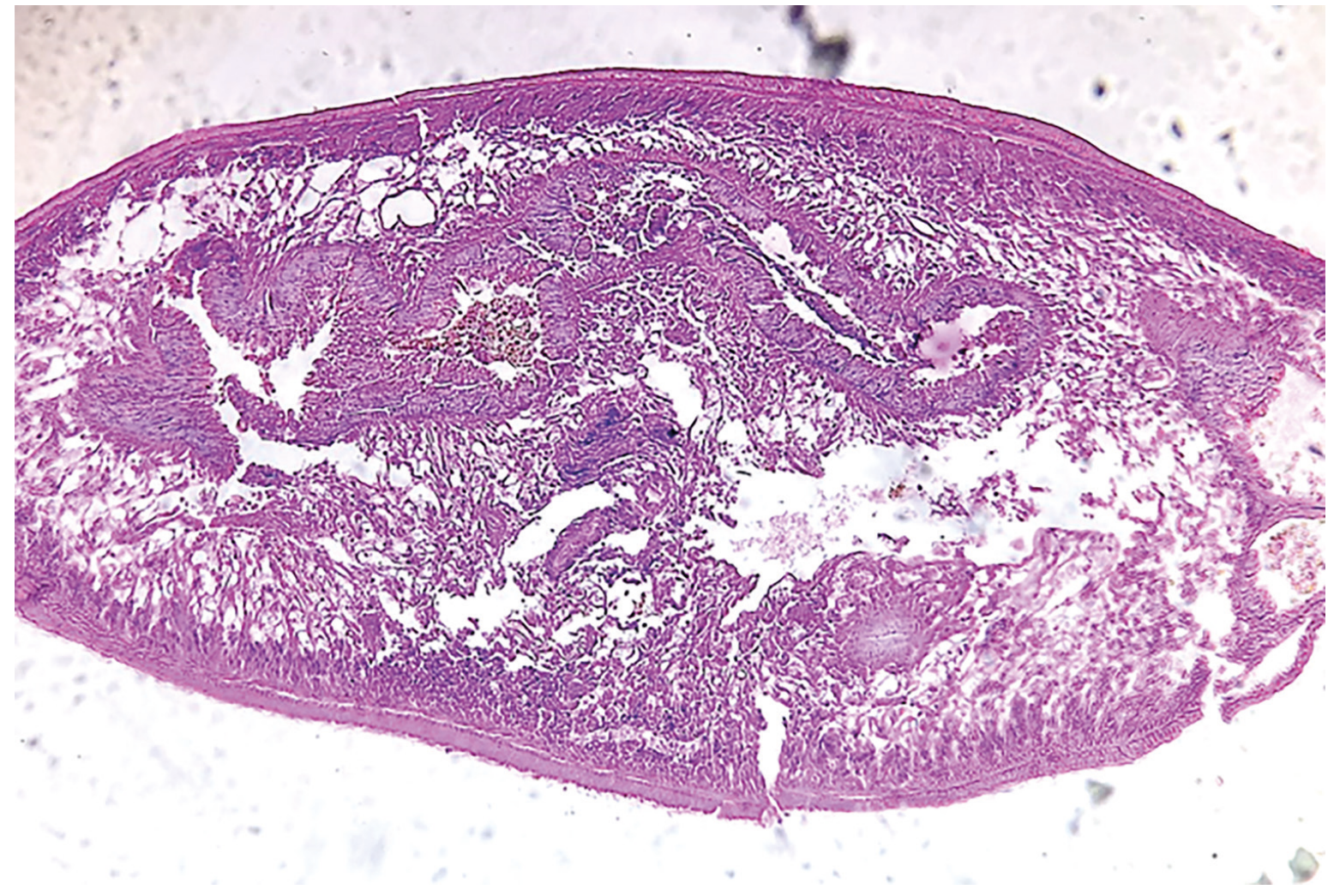

FIGURE 6. Microscopic image of foreign body corresponding to adult form of Paragonimus westermani (hematoxylin-eosin stain, original magnification $\times 100$ ).
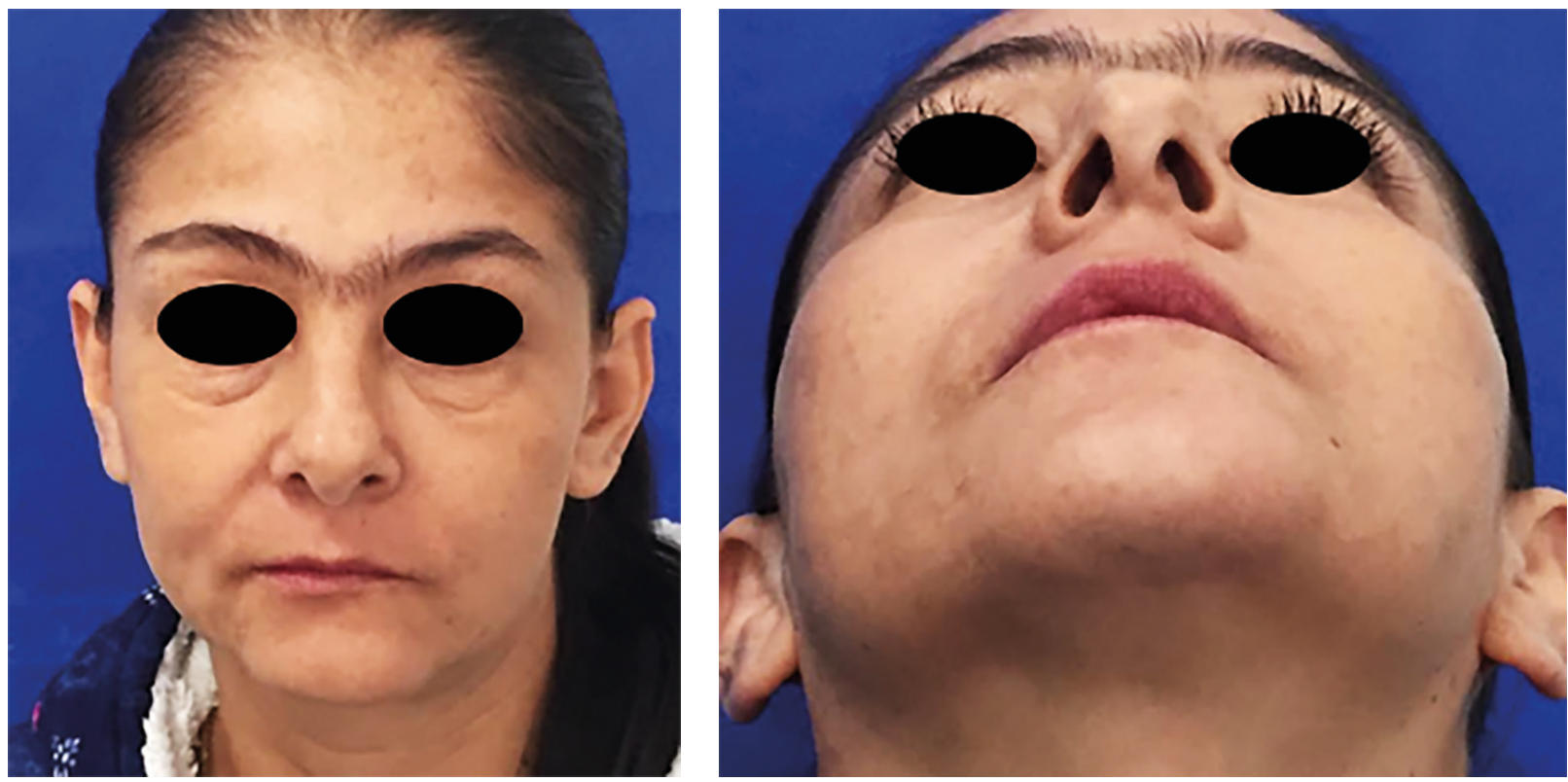

FIGURE 7. 1 month post-op after medical management with praziquantel showing no facial swelling. 


\section{DISCUSSION}

Paragonimiasis is a zoonosis described by Braun in 1899, caused by adult trematodes of Paragonimus genus that manifests itself as pathology located particularly in lungs and other extra pulmonary sites. Since its discovery, more than 40 species of microorganism have been reported in Asia, Africa and America, areas considered endemic especially in tropical areas. ${ }^{4}$

\section{LIFECYCLE}

Paragonimus westermani, considered the parasite most related to this pathology, has a life cycle that starts as a larva, initially colonizes the snail where it makes asexual reproduction. The cercariae leave the snail and invade the crustaceans which are consumed in raw or poorly cooked meat by humans. Metacercariae disembark in duodenum and migrate through peritoneum perforating abdominal wall and diaphragm until they locate in lungs parenchyma and form cystic cavities in a process that can take 2 to 8 weeks after contact with the contaminated meat. In some cases parasite locates in other parts of the body such as muscle, subcutaneous tissue, peritoneum, pleura, liver, intestine, testicles and brain. ${ }^{1}$ This microorganism is oval shaped flattened by its two faces and can reach a size similar to that of a coffee bean; Is a hermaphrodite parasite that has 2 testicles and 1 ovary; 2 suction cups that allow its adhesion to the tissue walls, an oral cavity and an excretory bladder.

\section{CLINICAL MANIFESTATIONS}

The clinical manifestations of paragonimiasis are variable depending on the severity of the infection, including urticaria, diarrhea, adynamia, abdominal pain, cough with expectoration, blood test in free eosinophilia, migratory nodules and abscesses, pleural effusion and hemoptysis, and in case of migration From parasite to central nervous system can show convulsions, hemiplegia and fatal encephalitis. $^{2}$

\section{DIAGNOSIS}

Expositional antecedents of the patient will give us indications to suspect paragonimiasis which can be confirmed by parasitological examinations and presence of Paragonimus in the sample of sputum or feces. Blood laboratories show leukocytosis with eosinophilia.

\section{TREATMENT}

Management of paragonimiasis is clearly pharmacological and gold standard is praziquantel; An anti-parasitic drug with success rate of $100 \%$ for paragonimiasis. This drug acts by increasing permeability to calcium in parasite cell wall causing involuntary contractions that end up rupturing membrane and causing death of the microorganism. The dose of administration is $75 \mathrm{mg} / \mathrm{kg} /$ day, divided in three doses for 2 to 3 days. It also describes the use of other drugs such as biotinol, an antiparasitic initially used veterinary that has been used for the management of paragonimiasis with success rates ranging from 60 to 80 percent, is considered the second choice for pharmacological management at doses of $40 \mathrm{mg} / \mathrm{kg}$ for 10 days.

Triclabendazole is useful for paragonimiasis management but presents a $20 \%$ success rate at a dose of $20 \mathrm{mg} / \mathrm{kg}$ and is still under study. ${ }^{5}$ In our case report we show the clinical characteristics of paragonimiasis reported in the literature as the migratory cutaneous nodules in the oral region that started in the left face to later migrate to the right side and mental region; cystic cavities present in lateral border of the tongue and oral mucosa; presence of pleural effusions, respiratory symptoms, eosinophilia and histopathological confirmation of microorganism in samples. During medical management a progressive increase of eosinophilia and persistence of clinical signs during the antibiotic and antiparasitic scheme with albendazole were evidenced, which effectively diminished until resolved in its totality after establishing the appropriate therapy with praziquantel at the dose reported in the literature.

\section{CONCLUSIONS}

- Pathologies of tropical endemic areas become diagnostic challenges when they occur in areas of low frequency.

- It is important to analyze the expositional antecedents of patients presenting with infrequent and non-pathognomonic findings.

- The complete medical record continues to be a 
fundamental tool for correct targeting towards the diagnosis and treatment of any pathological entity.

- Interdisciplinary communication and management leads to an effective and timely treatment for the patient.

- Documentation of zoonosis with colonization in the oral cavity is important to feed the world literature and allow an efficient diagnosis and efficient management of our patients.

\section{FUNDINGS}

No funding was needed.

\section{CONFLICTS OF INTEREST}

No conflicts of interest declared.

\section{PATIENT CONSENT}

Patient consent was given to publish clinical pictures.

\section{ACKNOWLED GMENTS}

None.

\section{REFERENCES}

1. Velez ID, Ortega JE, Velasquez LE. Paragonimiasis: a view from Columbia. Clin Chest Med 2002;23:42131.

2. Lupi O, Downing C, Lee M, Pino L, Bravo F, Giglio P, Sethi A, Klaus S, Sangueza OP, Fuller C, Mendoza N, Ladizinski B, Woc-Colburn L, Tyring SK. Mucocutaneous manifestations of helminth infections: nematodes. $J \mathrm{Am}$ Acad Dermatol 2015;73:947-57. https://dx.doi.org/10.1016/j. jaad.2014.11.034.

3. Schuster H, Agada FO, Anderson AR, Jackson RS, Blair D, McGann H, Kelly G. Otitis media and a neck lump-current diagnostic challenges for Paragonimuslike trematode infections. J Infect 2007;54:e103-6. https://dx.doi.org/10.1016/j.jinf.2006.05.011.

4. Davidson R, Brent A, Seale A. Oxford handbook of tropical medicine. 4th ed. Oxford: Oxford University Press, 2014.

5. Calvopiña M, Guderian RH, Paredes W, Cooper PJ. Comparison of two single-day regimens of triclabendazole for the treatment of human pulmonary paragonimiasis. Trans $R$ Soc Trop Med Hyg 2003;97:451-4. https://dx.doi.org/10.1016/ s0035-9203(03)90088-5. 